Media Industries 6.2 (2019)

\title{
The OTT TV Box as a Diasporic Media Platform
}

\author{
Ramon Lobato \\ RMIT UNIVERSITY \\ ramon.lobato [AT] rmit.edu.au \\ Pradip Sarkar ${ }^{1}$ \\ RMIT UNIVERSITY \\ pradip.sarkar [AT] rmit.edu.au
}

\begin{abstract}
:
The "TVbox," as it is colloquially known, is a specific type of over-the-top television streaming device that enables viewing of international television channels on the user's TV set. This article focuses on a distinct submarket of Android-based TV boxes (including both legal and pirate devices) that have emerged to service diasporic communities and that are sold informally in groceries, electronics stores, and online. Through a case study of Indian and South Asian TV box markets in Australia, we explore the distinctive business models, pricing structures, and anti-piracy enforcement strategies that characterize these markets. Our analysis shows how the TV box, notwithstanding its questionable legality, has become a global platform for what Naficy described as "decentralized global narrowcasting."
\end{abstract}

Keywords: OTT TV, Internet Television, Streaming, Distribution, Piracy

The "TV box," as it is colloquially known, is a specific type of over-the-top (OTT) television streaming device that enables viewing of live, linear television channels on the user's TV set via an HDMI connection. TV boxes come in many different varieties; however, our focus here is on a distinct submarket of Android-based devices that have emerged primarily to service diasporic media audiences and which includes both licensed and pirate devices. Examples include Chinese TV boxes such as TV Pad, EV Pad, Moon Box, and Lingcod TV; Indian and South Asian TV boxes such as Jadoo TV, YuppTV, LycaTV, XtremeBox, and WorldMax 4K; and Arabic TV boxes such as Cres TV, Shava TV, and MaxxTV. ${ }^{2}$ These are merely a few of the TV boxes that have appeared in recent years to cater to diasporic audiences. TV boxes are 
typically sold in groceries, spice shops, small electronics stores, street markets, and on social media. Widespread usage of these and other similar devices has been documented in Singapore, Hong Kong, Australia, Indonesia, the United States, the United Kingdom, and Canada, among other countries. ${ }^{3}$

This article provides an initial analysis of the TV box as a diasporic media device, focusing on its technical affordances and market structures. We begin by defining the TV box in relation to other OTT devices and theorizing its function as a generic hardware platform for linear television viewing. In the second half of the article, we offer a case study of desi (Indian and South Asian) TV box markets in Australia, focusing on the distinctive business models, pricing structures, and anti-piracy enforcement strategies that have emerged. Methods used include analysis of news media, case law, trade press, and observation of retail sites in Melbourne, Australia.

We argue that the TV box, a cheap and flexible hardware platform for internet-connected television, embodies a number of characteristics historically associated with diasporic media: Its mode of content distribution is transnational, while its mode of consumption and use is substantially informal. In their affordances, design, and everyday use, TV boxes have more in common with diasporic satellite television than with online streaming services such as Netflix and Hulu. We conclude that the TV box represents a fruitful object of analysis for media industry research because it productively challenges some of our assumptions about the future of television in the internet age.

\section{Defining the TV Box}

The distinctive characteristic of the diasporic TV box, as we define it here, is its unique commodity form. TV boxes are sold on a one-off basis as plug-and-play devices, rather than on a subscription basis through telcos and pay-TV providers (although hybrid business models are now appearing, as discussed below). The typical scenario of buying a TV box involves paying cash to an agent or retailer, in return for a device promising unlimited access to hundreds of live channels for a fixed or indefinite period. There is no need to sign up to a provider, nor is there any exchange of customer details, credit card numbers, or personal data. The TV box's status as an "off-the-shelf" commodity, rather than an element of a subscription package, helps to explain its distinctive commercial ecology, which encompasses both formal and informal markets, and the spaces in between.

TV boxes are functionally and visually similar to other OTT devices, including mainstream devices such as Roku and FireTV, in the sense that all these devices are black boxes or sticks that connect to the TV set. However, TV boxes-as we define the term here-are distinguished by their informal distribution. TV boxes are also categorically different from set-top boxes (STBs) supplied by telcos and pay-TV operators. STBs are typically locked to a particular network and supplied as part of a pay-TV subscription; in contrast, the TV boxes discussed here are flexible, plug-and-play devices that can be used on any network. Finally, the TV boxes discussed in this chapter are also not to be confused with pirate Kodi boxes, ${ }^{4}$ which are widely used for sports and pay-TV piracy but less commonly for diasporic media distribution. 
The historical origins of the TV box are challenging to trace because of the informal nature of the device and its circulation. The available evidence suggests that TV boxes started appearing in households in 2012 and that Chinese TV boxes were the first to achieve substantial take-up. By mid-decade, TV boxes had come onto the radar of pay-TV providers and rights-holders across Asia, Europe, and North America, who launched legal actions against the offending TV box brands. ${ }^{5}$ The following observations from a columnist in The Indian Telegraph, a newspaper for the Indian community in Australia, neatly capture the spirit of TV box use in the Indian Australian community circa 2014:

Of late there has been a huge proliferation of IPTV or INTERNET BOXES that allow you to watch any and all the content that we could possibly want. In the early days of online piracy it was a few Indian or Pakistani channels from back home that were available through these IPTV boxes but lately most of these boxes have tons of Hollywood and sports content as well. You see these products at stalls put up at various community festivals and events. Or you might have a friend who has a friend who can fix you up with these boxes. And its not hard to see why consumers take this route. When you ask a vendor the question if the product or service is LEGAL? We always get an answer "Ofcourse! It is."

Another example comes from Michael Keane, who in his book The Chinese Television Industry describes the experience of using a Chinese device called TVPad. Keane describes seeing an advertisement in a Hong Kong electronics market, which read as follows:

TVpad is the most popular TV box which allow (sic) you to watch 100+ Chinese TV channels, it looks exactly like a Roku or Apple TV. Has HDMI, USB, TFcard, Network connect and can stream up to 1080p, more and more Chinese use it as a TV overseas. It is also a great gift for Chinese!!

Although this device has since disappeared from the market, to be replaced by imitators such as EVPad, Keane remarks that TVPad "was making Chinese television accessible to overseas audiences," and as such may even function as "a window for China's soft power."7

As these two examples suggest, diasporic media markets were among the first to adopt the TV box en masse. The TV box, then, can be understood as a diasporic device in two distinct senses: first, because a large part of its user-base consists of diasporic citizens who use the device to watch TV from their home countries; and second, because diasporic markets are often underserved by established or mainstream media providers and are also characterized by a degree of distance from rights-holders and enforcement agencies in the home country, thus creating ideal conditions for media "workarounds" such as the pirate TV box. Our use of diasporic is therefore descriptive rather than prescriptive, consistent with the use of the term in recent diasporic media studies-referring to "mediated interactions, on flows of ideas, information, resources" between home and host country-rather than the more specific definition used in anthropological and cultural theory. ${ }^{8}$

The TV box may be described as diasporic in a third sense, too: because its design and user experience evoke longer histories of diasporic satellite television. In this sense, the TV box forms part of a lineage of television technologies enabling what Hamid Naficy famously described as "decentralized global narrowcasting," often described as ethnic or immigrant television. ${ }^{9}$ Since the 1990s, this phenomenon has been widely studied, debated, and theorized by television scholars, and in particular, scholars of Asian, Arab, and European 
television. Within the South Asian television literature, the resulting body of work includes studies of satellite channels targeting diasporic populations, such as MTV Desi; studies of the media consumption practices of diasporic South Asian audiences; and important theoretical work that reconceptualises South Asian television as a transnational medium "at large" and

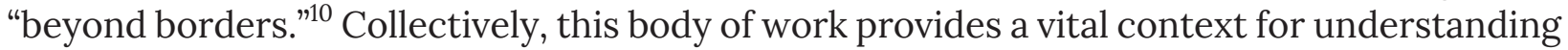
the historical origins of the TV box and its paradigm of long-distance narrowcast television distribution.

How does the TV box remediate this longer history of diasporic television? Notably, the TV box-while receiving its content over the Internet-offers a user experience that is much closer to the experience of watching satellite TV than an interactive online television service. The TV box is designed for viewers who prefer to view live, linear channels, remote control in hand. In other words, it offers a lean-back model of TV viewing which seems almost antiquated given the diverse interactive and mobile television services available to audiences today. The TV box is for viewers who want to watch TV in a traditional way-zapping between channels. Visually, most TV boxes bear a strong visual resemblance to cable and satellite pay-TV decoder boxes, which have been a fixture of many TV households since the 1970s. All this makes the TV box well suited for use within diasporic communities, especially among older viewers who may wish to stick with their established ways of watching television while also taking advantage of the wider range of channels and services available online. In other words, the TV box wears the shell of an older technology while fundamentally transforming its basic norms and affordances.

\section{What Kind of Platform Is the TV Box?}

Recent media scholarship has placed a strong emphasis on the platform as an analytical category. Following interventions by Bogost and Montfort, Gilespie, Srnicek, van Dyck, and others, the platform is now defined in several distinct ways which interact in academic usage, including a reprogrammable piece of hardware or software, an infrastructure enabling transactions across multisided markets, and a digital architecture for user interaction. ${ }^{11}$ Scholars have applied these understandings of the platform to diverse objects, from gaming consoles and social media services to automobile manufacturers and credit card companies-all of which can be described as platforms in one way or another. ${ }^{12}$ In recent years, there has also been a second wave of research on platformization as a sociotechnical process, ${ }^{13}$ along with a countermovement in media scholarship questioning the value of platform theory. ${ }^{14}$ In other words, the platform has become a widely used and hotly contested critical concept.

One strand of this literature has focused on the analysis of domestic media devices and their affordances. Bogost and Montfort, in their 2009 book Racing the Beam: The Atari Video Computer System, strongly emphasize the hardware dimension of devices as the base level upon which software systems are built. For Bogost and Montfort, the platform is a reprogrammable system that begins with a physical device: "In general, platforms are layeredfrom hardware through operating system and into other software layers." 15 This notion of the platform as an integrated hardware/software system has diminished somewhat in recent platform studies, as attention drifted to virtual platforms such as social media services and 
ride-sharing apps. However, it remains a useful model for studying digital media. Within media industry studies, there is also considerable value in retaining this device-centered understanding of the platform for it enables us to see how different "layers" within a media device-which each have their own industrial histories-interact.

The TV box represents a useful case study within these debates because it can be described as a "platform" in at least three senses. First, the TV box is a distribution platform for the content that it makes available to audiences, following the common (but imprecise) usage of this term in media and video business. Second, the device functions as a hardware platform for the operating system, which in turn functions as a software platform for the apps it carries. Third, the TV box is a commercial platform in the sense that it monetizes viewer attention, which can be purchased by third-party advertisers (as in the case of YuppTV, described below). Hence, the TV box is platform-like in the industrial, computational, and economic senses of the word.

A key factor underlying the proliferation of TV boxes over the last decade is Google's opensource mobile operating system, Android OS. Android is the operating system of choice for almost all of the pirate boxes in circulation, and many of the legal boxes as well. Android was first released as a mobile operating system in 2008. Later versions of Android could be adapted for use on television sets, thus enabling navigation with a remote control. Importantly, Android and its various "forks" (custom versions based on Android source code) could be installed at no charge to device manufacturers. The free nature of Android, combined with consumer familiarity with the Android mobile OS, made it an appealing choice for device manufacturersespecially several Chinese electronics manufacturers who started mass-producing Android boxes in enormous quantities and selling them at low cost. These boxes were then resold to OTT providers around the world and also to wholesalers and distributors who would resell the boxes direct to consumers or via e-commerce websites, especially Alibaba.

It should be emphasized that these Android boxes were not official Google products; instead, they used a fork of Google's Android OS that would be customized to appear like a pay-TV interface, with the TV box's own apps placed prominently in the home screen. In most cases, users of these forked Android boxes were able to download additional apps through the Play Store, so they did not perceive a significant difference from the "real" Android OS. This platform flexibility, combined with the millions of free and paid apps available in the Android ecosystem, constituted a significant commercial advantage for Android-based boxes compared with other STBs using proprietary operating systems, which had fewer features and lower consumer brand recognition. It also allowed TV box operators, especially the pirate operators, to augment their TV and movie offerings with a range of other services, including games, educational apps for kids, adult content apps, and karaoke apps (the latter are especially common in Chinese TV boxes). Many pirate TV box providers prefer to preinstall as many apps as possible to increase the perceived value of their device; hence, it is not uncommon to find TV boxes that feature both educational apps and adult apps in the one device, although a PIN protection system is often included so that parents can restrict access. Of course, many users ignore these extras and stick to the linear TV channels that are the main appeal of the TV box.

Our point here is that the development of the TV box as a multifunctional diasporic media device was inseparable from the development of its dominant operating system-Android. In 
this sense, the TV box is best understood not as a single platform but as a series of nestled, interconnected platforms, including the physical device, the Android operating system, and the various apps and advertising systems that run on top of this OS.

\section{Formal and Informal Variants of the TV Box}

There are two main types of diasporic TV box: legal and pirate devices. Legal TV boxes are often supplied by television networks targeting offshore viewing communities or by established diasporic media providers, including satellite TV distributors, who are now using internet protocol television (IPTV)/OTT distribution for its cost advantages. For example, TFC Box is a plug-and-play device operated by the Filipino media conglomerate ABS-CBN, based in Quezon City, Philippines. The TFC Box is sold widely throughout the Filipino diaspora and can be purchased on a one-off basis for around A\$300 (including a one-year subscription) or via monthly subscription payments (A\$35/month). MyTV Box is another legal diasporic TV box, developed by the Hong Kong television network TVB. TVB has a long history of exporting Chinese media into overseas markets since the 1970s, via satellite feeds, video sales, and online services. ${ }^{16}$ However, TVB, ABS-CBN, and other legal providers offering OTT boxes compete with pirate boxes that frequently offer the same channels (or an expanded range of channels) at a lower price. For this reason, both ABS-CBN and TVB have been very proactive in initiating legal action against pirate box providers, distributors, and retailers. ${ }^{17}$

The informal end of the spectrum consists of pirate TV box brands sold by agents and resellers working on a commission basis out of shops, groceries, electronics stores, and on social media. Pirate TV boxes typically offer a very wide range of channels, usually in the hundreds or thousands, along with a large video-on-demand library of movies and TV shows. It is impossible to know the number of pirate TV boxes in use. Research by anti-piracy agencies offers some indicative figures, although these are likely to be inflated for lobbying purposes. The Cable and Satellite Broadcasting Association of Asia (now the Asian Video Association) has claimed that use of pirate TV boxes is estimated at around 24 percent of the population in Hong Kong. "Among the most popular illegal streaming pirate TV boxes for Hong Kong consumers," noted the study, "were BossTV (9\%), Ubox (7\%), EVPad (6\%), Lingcod (5\%), and Magic Box (4\%)." A similar study conducted in Singapore suggests that 7 percent of the population use pirate TV boxes. ${ }^{19}$

Other available data suggest a comparable level of uptake. For example, Italian anti-piracy agencies claim there are five million "IPTV pirates" in Italy, most of whom are using illegal TV boxes, out of a population of sixty million. ${ }^{20}$ In North America, an authoritative network traffic study by Sandvine estimated that around 6 percent of internet traffic in North America is due to illegal subscription TV piracy, the vast majority of which "is driven by purpose-built set-top boxes (STBs) that are designed to faithfully recreate the experience of using a settop box with a traditional cable or satellite television subscription"-in other words, pirate TV boxes. ${ }^{21}$ These various studies suggest TV box piracy is a more or less global phenomenon and includes both the diasporic boxes we describe here as well as Kodi boxes and other devices used more for live sports, movie, and mainstream cables/satellite TV piracy. However, the scale of activity from country to country is impossible to verify. 
Since 2016, litigations against diasporic TV box operators by copyright holders have become common in a number of jurisdictions, including Australia, Singapore, the United States, and Canada. $^{22}$ The complainants are typically pay-TV providers such as Dish TV or TVB. The TV box anti-piracy agenda also overlaps with the wider campaign against "illegal streaming devices," which has been a major feature of anti-piracy strategy over the last few years. ${ }^{23}$ These various enforcement activities and their associated trail of public court documents provide useful descriptive information on the technical workings of pirate TV boxes, which rely on designated IP addresses to provide channel feeds, EPG (electronic program guide) information, and software updates. ${ }^{24}$ Most TV boxes are presumed to use a variation of this basic method and are therefore vulnerable to IP-blocking requests where permitted under national law. For consumers, the implication is that spending hundreds of dollars on a TV box is a risky endeavor. Internet forums are littered with complaints from users, who describe how their pirate TV boxes suddenly stop working as a result of anti-piracy enforcement.

\section{Case Study: Desi TV Boxes in Australia}

This section of the article reports on our observations of TV box markets catering to desi audiences in Australia. The term desi refers to people and cultures that originate from the Indian subcontinent or South Asia, including India, Pakistan, Bangladesh, Nepal, Sri Lanka, and the Maldives. Since 2017, we have been studying the TV boxes catering to these various diasporic communities, whose media environments are closely interconnected. Through observation of diasporic community media, social media, online trading platforms (eBay, Gumtree), and physical retail sites in Melbourne (groceries and spice stores), we were able to assemble a general picture of how desi TV box markets work. Below, we describe the key TV box brands, pricing, retail dynamics, and copyright enforcement dynamics.

At the time of writing, there are three established TV box brands providing desi TV content available in Australia, with several others competing around the margins (see Figures 1-3 for examples of desi and other boxes in typical retail environments). At the formal end of the spectrum is YuppTV, an established OTT provider with offices in Hyderabad, India, and Georgia, USA. The service carries several hundred South Asian linear channels and a wide variety of on-demand movies, and TV shows, under a bundle called YuppFlix. Subscription packages are offered at various price points, organized according to language. Offerings include "combos" of 166 or more channels in two prespecified languages (such as Sinhala and Tamil for Sri Lankan customers, or Malayalam and Tamil for Southern Indian viewers) and two languages along with Hindi, the latter granting customers access to pan-Indian or pansubcontinental entertainment, such as Bollywood films and music videos.

YuppTV was initially marketed as a standalone TV box or USB dongle and sold through agents, mostly out of spice stores, groceries, and electronics shops within the diaspora. More recently, YuppTV has shifted toward a smart TV app distribution model, which does not require a separate box (see Figure 3), reflecting the wider consumer trend toward smart TV adoption. YuppTV now also comes preinstalled as an app on many smart TVs, including Sony Bravia TVs, sold in Australia, and it also has its own video advertising operation, carrying ads from both local and international advertisers. In this sense, YuppTV operates in the spirit of 
an entrepreneurial tech company rather than an old-fashioned diaspora media provider. The company has a head office in the United States, and in 2016 received US\$50 million in venture funding from Emerald Investments (a division of the major US venture capital firm KKR). As a company, Yupp appears to have one foot in the Indian diaspora and the other foot in Silicon Valley.

YuppTV boxes are available in Melbourne at a cost of around A\$200 to A\$300 via resellers in the community, on social media, on eBay and Gumtree, and through the YuppTV website. This price includes a one-year subscription to the service, after which users must

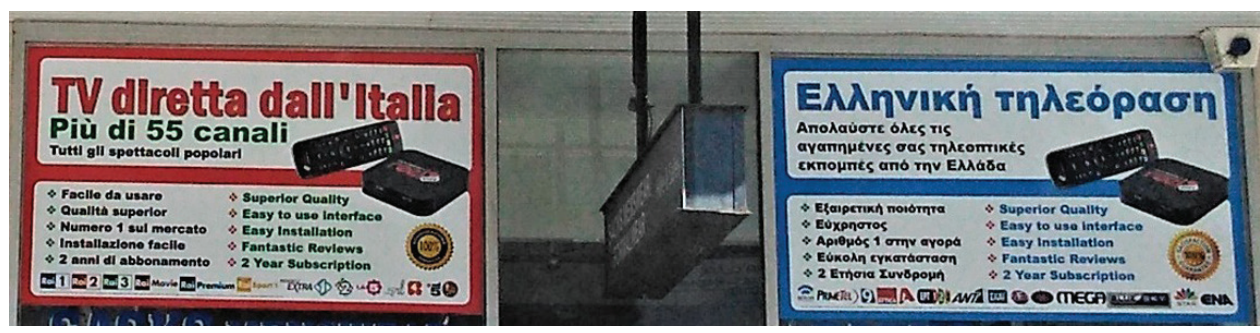

Figure 1. Greek and Italian TV boxes on sale in Melbourne, 2018.

Source. Ramon Lobato.

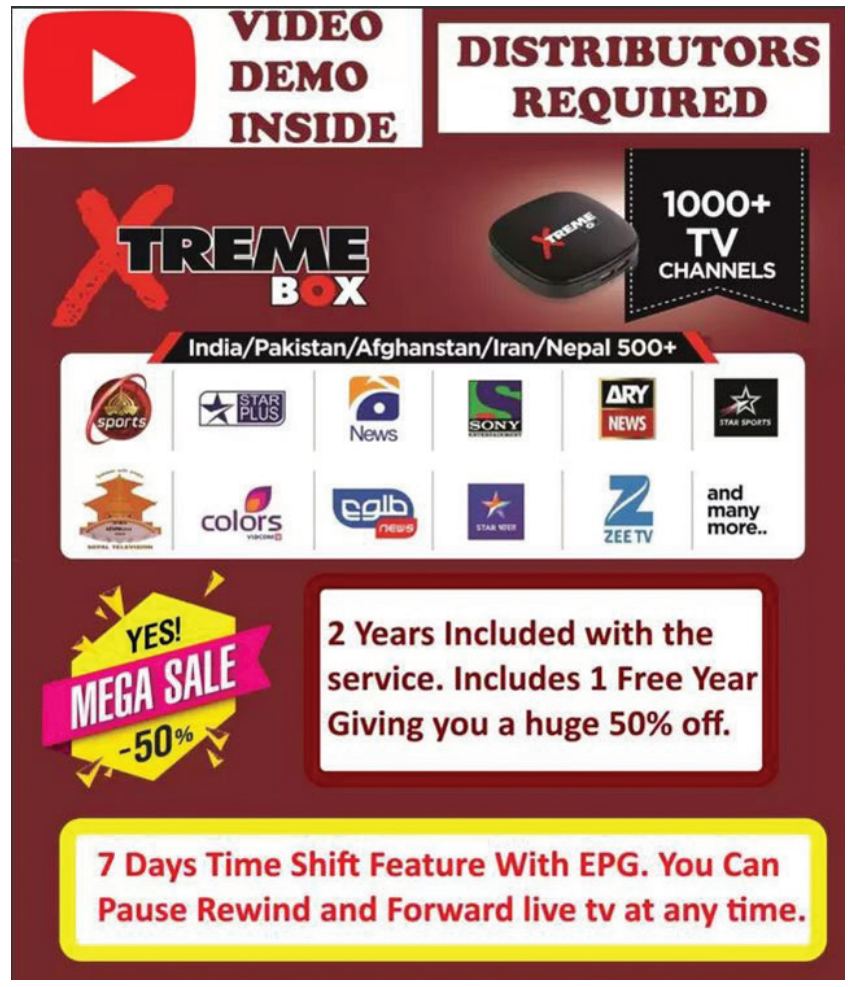

Figure 2. Advertisement for XtremeBox posted on Gumtree.com.au, April 2019. 


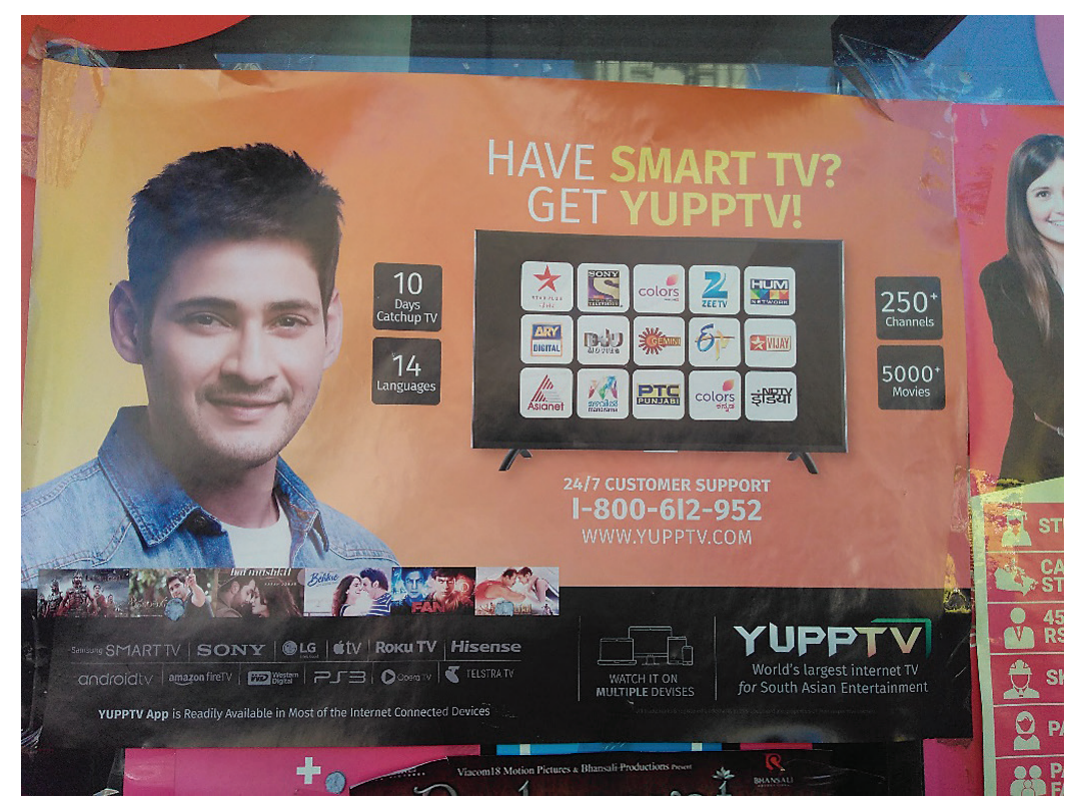

Figure 3. YuppTV poster in a grocery store, Melbourne, promoting the YuppTV app.

Source. Ramon Lobato.

resubscribe for an additional charge (around A\$200 per year). Alternatively, users can subscribe via the YuppTV smart TV app for A\$25 per month. The prices charged for a YuppTV subscription, whether via box or app, are comparable to the cost of a satellite TV subscription from an Australian provider catering to the South Asian communities. This is definitely not a cheap or free service. Licensing of content is conducted formally, but distribution of the box is still largely carried out informally.

Another legal TV box is LycaTV, an offshoot of the Lyca Group business founded by the London-based Sri Lankan entrepreneur Allirajah Subaskaran. Lyca is best known for its LycaMobile service which offers low-cost mobile calls to migrant communities in Europe, Africa, and Asia. (The company is also known in the United Kingdom for its alleged links to a money-laundering and political donation scandal. ${ }^{25}$ ) In Australia, LycaTV boxes are sold for around $\mathrm{A} \$ 150$ at groceries, electronics stores, and mobile stores and include a year's service. Once the year has expired, the box can then be "recharged" for an additional A\$159. The LycaTV service, which specializes in Tamil films and South Indian and Sri Lankan programs, carries around sixty channels and thousands of on-demand movies. LycaTV also offers a similar box-based and app-based OTT service for other ethnolinguistic communities, including Sinhalese, African (both English and Francophone), and Filipino, all based on the same platform. In this sense, LycaTV's strategy has been to leverage its status as a low-cost mobile SIM and credit company-with its extensive agent and distributor base in diasporic retail sites around the world-into the adjacent market of OTT television.

A third TV box, JadooTV, has also been widely used among the Indian diaspora in Australia, although it is less frequently seen now. Jadoo has a long and checkered history in OTT distribution. In 2014, four Jadoo associates were arrested in Hyderabad and charged with pirating satellite feeds from local pay-TV channels. ${ }^{26}$ Current Jadoo management denies any 
association with piracy, however, and since then Jadoo has grown into a major global platform for South Asian television. The Jadoo service now carries hundreds of different channels arranged into different packages (Indian, Afghan, Arabic, Bangla, Pakistani, Punjabi). It also carries Eros Now, the subscription video-on-demand service from the Indian media giant Eros International. Jadoo boxes cost around A\$300, and there is a network of resellers in Australia who promote their offerings through social media.

These three services-YuppTV, LycaTV, and Jadoo-are now well established in Australian desi media markets. Their apps are available across most of the major mobile and smart TV operating systems, but each company continues to offer their TV box as an alternative, designed for those users who prefer a traditional STB-based television-viewing experience. In all three cases, the programming, app distribution, and marketing side of their business has become more formal in recent years, although there is still a degree of unpredictability when it comes to programming and customer service. Hence, the political economy of these TV boxes is characterized by a distinctive mix of formality and informality.

The rest of the TV box market in Australia consists of pirate devices. These boxes, which we will not identify here, are sold through the same informal retail sites described above. The most widely sold of these boxes costs A $\$ 380$, including a one-year subscription-a very hefty price tag for a TV box. The distinguishing feature of this box is its international channel range. As one store manager described to us, the box features "thousands of channels," including $\mathrm{HBO}$ and other premium English-language channels, and various international sports channels that are not carried by the legal TV boxes (no doubt due to rights availability and licensing costs in the formal market). The sports channels offer ample coverage of live cricket, which is a particular selling point. This particular pirate TV box also features a variety of on-demand movies, which appear first in "cam" versions (i.e., camcorded versions illegally taped in theaters). Over time, these movies are replaced by more legitimate-looking versions ripped from a DVD or a digital stream-which suggests that the boxes take their feeds from online streaming servers and cloud storage sites used widely in the online piracy scene. ${ }^{27}$ After the two-year subscription expires, the box stops working and the customer must return to the store to "recharge" the box at a cost of around A\$200 per year.

Needless to say, the emergence of pirate TV boxes and other pirate OTT services has angered distributors of legal desi media in Australia. Representatives from Vision Asia, an NRI satellite and IPTV provider, complained publicly in 2014 about the commercial threat of TV box piracy to legal satellite TV distributors, noting that there are more pirate TV boxes in the Australian market than legitimate subscribers. ${ }^{28}$ The Vision Asia service subsequently disappeared from the market.

Another affected industry consists of informal satellite dish installers, who have been servicing desi audiences in Australia for many years. These installers charge several hundred dollars for a satellite installation, allowing access to either free or paid satellite channels. Both models are vulnerable to informal competition from pirate TV boxes because of the lower overall subscription and purchase costs (generally), the higher number of channels, and the flexibility of a plug-and-play device-which is much better suited to international students and other users living in rented accommodation, than traditional satellite installation, which requires permission from a property owner to install a dish on the roof. 
The TV box markets that we have described above are consistent with a longer tradition of desi video distribution in Australia. TV boxes clearly have their roots in the informal economy but have established some formal business models on top of this foundation. They also form part of a wider social economy of consumption and are deeply integrated into the retail channels used for other kinds of desi goods, from groceries to SIM cards. In this sense, the TV box, rather than instituting a whole new sphere of cultural circulation, augments preexisting systems of circulation that have been established over decades of diasporic media enterprise. This recalls arguments made by Adrian Athique in his important work on Indian cinema piracy in Australia. ${ }^{29}$ Athique argues that

the pattern of distribution achieved by Indian films through playback media over the last 25 years can [...] be seen as exemplary of the effective targeting of a dispersed, (mostly) niche audience through demand-driven film distribution undertaken along a chain of relatively small entrepreneurs. In this sense, the Indian film provides a compelling example of what can be achieved when a technological innovation is successfully conjoined with the economic ideology of the free market in order to provide an "on-demand" service to consumers. ${ }^{30}$

The logic described by Athique-in which a new media innovation is channeled through the informal economy to service dispersed export markets-neatly describes the current situation with TV boxes. The TV box is an extension of what Athique describes as diasporic "playback media"; it builds on the distribution patterns established through VHS and optical disk media (VCDs and DVDs), which used the same retail sites and modes of distribution. The end result in both cases is an efficient yet informal system of media distribution that fills a gap in the market, making films and TV content available in many different languages to audiences throughout Australia.

As with most media products aimed at the South Asian diaspora, grocery and spice shops serve as distribution points for TV boxes in urban Australia. Such family-run retail outlets can be found in the main cities of Australia, with a particular concentration of such outlets in Melbourne and Sydney, both with sizable desi populations. ${ }^{31}$ Apart from selling groceries and spices to their fellow countryfolk, these shops also serve as media hubs and offer remittance services to relatives back home. As media hubs, they used to offer video rentals where copies of Bollywood and Indian regional films, Pakistani TV dramas, and Indian TV serials could be borrowed on VHS tapes. ${ }^{32}$ As CD and DVD burners dropped in prices, the VHS tapes were replaced with VCD and DVD copies. The migration of pirated films onto VCDs and DVDs changed the business model in that rentals were no longer part of the shops' portfolio. Instead, disks were sold outright, which can be attributed not only to the falling prices of CD/DVD burners and disks, but also to the speed at which multiple copies could be made. The shops also sold copied audio CDs of popular film soundtracks, pop music, and devotional songs, and phone cards that advertised relatively cheap calls to the countries of origin. Other media products included half a dozen free local desi community publications and some imported publications from the countries of origin.

With the advent of video streaming services and TV boxes, the shops have switched from stocking shelves of the latest blockbusters and TV shows on DVDs, to an increased focus on TV boxes and subscription services. Pirated audio CDs and phone cards also began to 
disappear as download platforms, serving as mp3 aggregators, and smartphone apps, such as WhatsApp and Viber, grew in prominence. Thus, spice shops continue to play a prominent role as "unofficial" distributors of desi media in Australia with the capability to "supply a wide range of [.. .] media products to a diverse and typically dispersed customer base."33

Interestingly, the brand of TV boxes stocked within a particular store bears a relationship to the ethnic community that forms the core customer base of that store. Shops catering to mostly South Indians and Sri Lankan Tamils tend to stock LycaTV, which specializes in films and programs in the Southern Indian languages of Tamil, Telugu, Kannada, and Malayalam, while Jadoo and MaxxTV appeal to Indian Punjabi and Pakistani markets. Clearly, these networks are not servicing one single diaspora but many different disaporas, representing subnational and transnational identities from across India, Pakistan, Bangladesh, Sri Lanka, and Nepal. Each of these diasporic "sphericules" 34 is characterized by distinct regional, linguistic, and taste affinities, which different TV box brands attempt to satisfy in different ways. While some content, such as live cricket, have a wide audience, other content such as Telugu movies are more specific in their appeal. In all cases, language plays a more important role in programming selection than national origin. In this regard, the structure of TV box markets reflects the complex demography of South Asian diasporas in Australia. These diasporas consist of ethnolinguistic groupings that structure media consumption patterns while also shaping preferences for particular eateries and grocery stores, which in turn form the distribution hubs for the TV boxes.

\section{Conclusion}

Our analysis of the TV box and its use within diasporic media markets has established that this relatively simple device is now at the center of a complex industrial ecology that extends older forms of diasporic media provision. The unique commercial form of the TV box-as an off-the-shelf retail product-distinguishes it from the many other subscription-based or free OTT TV services and from legacy pay TV. The boxes we have described above are all similar, in the sense that they are Android-based devices that replicate a linear experience of cable or satellite television viewing, but the diasporic publics addressed by these devices are very diverse, as is the range of live and on-demand content they distribute in many different languages. There is still a great deal we do not know about how these boxes are used in everyday practice.

Our analysis of TV box markets is one fragment of a larger story. Our observations refer to one particular city, Melbourne, and to South Asian diasporic uses of the TV box within this city. We do not make large claims about how TV box markets work globally, aside from noting the general features of the device (its platform-like qualities, its plug-and-play versatility, its informality, and its typical commodity forms). Our research certainly suggests there are commonalities in how the TV box is being localized to serve diasporic audiences in various countries, but the configuration of each market will always be different due to distinct cultural, economic, technological, and regulatory norms.

The future of the OTT TV box is somewhat uncertain at the time of writing. It is possible that the TV box could turn out to be an ephemeral rather than a permanent feature of diasporic 
television landscapes. As noted earlier, pirate TV boxes are increasingly vulnerable to antipiracy enforcement by rights-holders, while legal providers are shifting away from the TV box model in favor of smart TV apps and mobile apps, which eliminate the need for a TV box retail network. Meanwhile, older diasporic audiences who prefer a linear, lean-back TV experience are reducing in number, making way for younger, mobile-first users who are happy to watch television on the small screen. In other words, it is possible that the TV box, as described above, may turn out to be a bridging technology-a device whose primary function is to connect the experiential norms of cable and satellite television viewing with the new world of OTT distribution. It is still too soon to tell, of course.

Our approach in this article has been to provide an overview of the diasporic TV box as a media platform, focusing on its technical affordances and characteristic market structures. Future research in this area could potentially take a variety of forms. Interviews with suppliers and resellers would likely reveal a great deal more about the political economy of these boxes. Ethnographic audience research presents rich possibilities for understanding the experiences of OTT television consumption in the domestic setting. The possibility of comparative research is also enticing: Research could explore how different diasporic groups (e.g., Chinese, South Asian, and Arabic diasporas) have localized the TV box in distinctive ways, or how transnational diasporic communities across two or more locales (e.g., Tamils in Australia and the United Kingdom) have similar or different experiences.

Embedded in the context of diasporic cultural studies, the resulting analysis would likely appear rather less device-centric than our account and might instead foreground the larger lifeworlds into which the TV box has become integrated. For the purposes of media industry research, however, we hope this article has provided an initial mapping of the landscapeand thus a starting point for understanding how a specific digital media hardware/software platform has enabled diverse distribution and consumption practices across both formal and informal markets.

\section{Acknowledgment}

Many thanks to Yu-Kei Tse, Alexandra Heller-Nicholas, Yee Man Louie, and Alexa Scarlata for expert advice and assistance over the course of this research.

${ }^{1}$ Dr. Ramon Lobato is senior research fellow in the School of Media and Communication at RMIT University, Melbourne. His research explores video markets, distribution, and piracy. Ramon is the author of Shadow Economies of Cinema (2012), The Informal Media Economy (2015, with J Thomas) and Netflix Nations (2019). Dr. Pradip Sarkar is a lecturer in the School of Business Information Technology and Logistics at RMIT University, Melbourne, with an avid interest in informal media ecologies and digital workarounds in the creative industries.

${ }^{2}$ For more information on these and other TV boxes in the context of wider trends in digital television piracy, see Ramon Lobato, "Evolving Practices of Informal Distribution in Internet Television", in Routledge Companion to Global Television, ed. Shawn Shimpach (London: Routledge, 2019), 479-487. 
${ }^{3}$ Cases brought by rights-holders against pirate diasporic TV box operators include: Alliance for Creativity and Entertainment vs Tickbox TV (US, 2018); Dish Network vs. Spider-TV and Tiger Star (US, 2018); Coalition against Piracy vs. Synnex Trading (Singapore, 2018); Dish Network vs. Shava TV and Cres IPTV (US, 2017); ABS-CBN Corp vs. Ed Casinillo and Roxy Gonzales (Philippines, 2017); Dish Network vs. Loolbox (US, 2017); Village Roadshow and TVB vs. HD Subs (Australia, 2018); and so on. See also: Sandvine, 2017 Global Internet Phenomena-Spotlight: Subscription Television Piracy (Waterloo, CA: Sandvine Incorporated ULC, 2017); Andrew McDonald, "CASBAA: 24\% of Hong Kong Viewers Use Pirate TV Boxes," Digital TV Europe, June 25, 2018, https://www.digitaltveurope.com/2018/06/25/casbaa24-of-hong-kong-viewers-use-pirate-tv-boxes/; "Filstream pirate box kingpins arrested by Shenzhen police," PEP.ph, March 4, 2017, https://balitangamerica.tv/ filstream-illegal-pirate-box-kingpins-arrested-by-shenzhen-police/ (regarding diasporic Filipino TV boxes in China); Asia Video Industry Association, Indonesia in View (Hong Kong: Asia Video Industry Association, 2019), 5.

${ }^{4}$ The term Kodi box refers to a generic Android streaming devices equipped with the open-source media player Kodi (formerly XBMC). Kodi allows installation of unofficial add-ons that enable easy access to pirated film and TV content.

${ }^{5}$ See note 2 above.

${ }^{6}$ Twinkle Ghosh, "The World Wide Web of Piracy," The Indian Telegraph, August 11, 2014, https://theindiantelegraph.com.au/the-world-wide-web-of-piracy/.

${ }^{7}$ Michael Keane, The Chinese Television Industry (London: British Film Institute, 2015), 2.

${ }^{8}$ Roza Tsagarousianou and Jessica Retis, "Diasporas, Media, and Culture: Exploring Dimensions of Human Mobility and Connectivity in the Era of Global Interdependency," in The Handbook of Diasporas, Media, and Culture, ed. Roza Tsagarousianou (London: Routledge, 2019), 5. In contrast, for a classical definition of diasporic consciousness, see James Clifford, "Diasporas," Cultural Anthropology 9 (3, 1994): 302-38.

${ }^{9}$ We refer here specifically to Naficy's "transnational mode" of narrowcasting. See: Hamid Naficy, "Narrowcasting in Diaspora: Middle Eastern Television in Los Angeles," in The Media of Diaspora: Mapping the Globe, ed. Karim H. Karim (London: Routledge, 2003), 51-62. On transnational and diasporic satellite television, see also: Asu Aksoy and Kevin Robins, "Thinking across Spaces: Transnational Television from Turkey," European Journal of Cultural Studies 3 (3, 2000): 343-65; Stuart Cunningham and John Sinclair, eds., Floating Lives: The Media and Asian Diasporas (Saint Lucia: University of Queensland Press, 1999); Naomi Sakr, "Diversity and Diaspora: Arab Communities and Satellite Communication in Europe," Global Media and Communication 4 (3, 2008): 277-300.

${ }^{10}$ Madhavi Mallapragada, "Mixed Signals: MTV Desi, South Asian American Audiences and the Discourse of Ethnic Television," South Asian History and Culture 3 (4, 2012): 549-65; Ananda Mitra, "The Trans-Indian: Perspectives on Real vs. Virtual Identity in the Age of the Internet," in Indian Transnationalism Online: New Perspectives 
on Diaspora, ed. Ajaya Kumar Sahoo and Johannes G. de Kruijf (London: Routledge, 2016), 47-61; Aswin Punathambekar and Shanti Kumar, Television at Large in South Asia (London: Routledge, 2015); Michael Curtin and Hemant Shah, Reorienting Global Communication: Indian and Chinese Media beyond Borders (Champaign: University of Illinois Press, 2010).

${ }^{11}$ Jose van Dijck, Thomas Poell, and Martijn de Waal, The Platform Society: Public Values in a Connective World (Oxford: Oxford University Press, 2018), 4. See also: Tarleton Gillespie, "The Politics of 'Platforms'." New Media \& Society 12 (3, 2010): 1-19; Nick Srnicek, Platform Capitalism (Cambridge: Polity Books, 2016); Ian Bogost and Nick Montfort, "New Media as Material Constraint: An Introduction to Platform Studies" (paper presented at the 1st International HASTAC Conference, Duke University, Durham, NC, April 19-21, 2007, http://www.bogost.com/downloads/bogost\%20 montfort\%20hastac.pdf.)

${ }^{12}$ For example, on the credit card as a platform, see David S. Evans and Richard Schmalensee, Paying with Plastic: The Digital Revolution in Buying and Borrowing, 2nd ed. (Cambridge, MA: The MIT Press, 2015); on Rolls Royce as a "product platform," see Srnicek, Platform Capitalism, 37-39.

${ }^{13}$ Adrian Athique and Vibodh Parthasarathi, this issue; Anne Helmond, "The Platformization of the Web: Making Web Data Platform Ready," Social Media + Society 1 (2, 2015): 1-11; Jean-Christophe Plantin, Carl Lagoze, Paul N. Edwards, and Christian Sandvig, "Infrastructure Studies Meet Platform Studies in the Age of Google and Facebook," New Media \& Society 20(1, 2016): 293-310.

${ }^{14}$ Amanda Lotz, "Are Facebook, Google, and Amazon the Future of Media?," Council for the Humanities, Arts and Social Sciences Public Lecture, April 4, Queensland University of Technology, Brisbane, Australia.

${ }^{15}$ Ian Bogost and Nick Montfort, Racing the Beam: The Atari Video Computer System (Cambridge, MA: The MIT Press, 2009).

${ }^{16}$ Michael Curtin, Playing to the World's Biggest Audience: The Globalization of Chinese Film and TV (Berkeley: University of California Press, 2007), ch. 5.

${ }^{17}$ See note 2 above.

18 McDonald, "CASBAA."

${ }^{19}$ Sycamore Research, "An Exploration of Piracy and Illicit Streaming Devices (TV Boxes) in Singapore," Sycamore/Cable and Satellite Broadcasting Association of Asia, Singapore, 2017, http://casbaa.com/wordpress/wp-content/uploads/2017/09/ Sycamore-Study-Slides-Complete-Version.pdf.

${ }^{20}$ Chris Dziadul, "IPTV Drives Piracy in Italy," Broadband TV News, December 4, 2018, https://www.broadbandtvnews.com/2018/12/04/iptv-drives-piracy-in-italy/.

${ }^{21}$ Sandvine, 2017 Global Internet Phenomena, 4.

${ }^{22}$ For example, in December 2017, TVB filed a complaint in Australia's Federal Court seeking to block IP addresses used by seven pirate TV boxes: A1, BlueTV, EVPAD, FunTV, MoonBox, Unblock, and hTV5. The locations provided various services including program guides and software updates, This request was duly granted by the Court some months later. See: Rohan Pearce, "Court Backs TV Company's 
Bid to Block Illicit Set-Top Box Streaming," Computerworld, September 21, 2018, https://www.computerworld.com.au/article/647091/court-backs-tv-com pany-bid-block-illicit-set-top-box-streaming/.

${ }^{23}$ Ernesto, "Hollywood Sees Illegal Streaming Devices as 'Piracy 3.0,"' Torrent Freak, June 2, 2017, https://torrentfreak.com/hollywood-sees-illegal-streaming-devicesas-piracy-3-0-170502/.

${ }^{24}$ See, for example, Dish Network L.L.C. et al v. Shava IPTV Network LLC et al, Virginia Eastern District Court Case No. 1:15-cv-00706, amended complaint filed 11 January 2016. This lawsuit targeted the Ontario-based operators of a major Arabic-language TV box.

${ }^{25}$ See the three-part investigative report by BuzzFeed News in the United Kingdom, beginning with: Heidi Blake, Michael Gillard, Tom Warren, Jane Bradley, and Richard Holmes "This Tory Donor Was Secretly Filmed Dropping Cash-Stuffed Rucksacks at Post Offices," BuzzFeed News, October 6, 2015, https://www.buzzfeed.com/ heidiblake/this-tory-donor-was-secretly-filmed-dropping-cash-stuffed-ru.

26 "Satellite TV Racket Busted in Hyderabad," The Times of India, June 30, 2014, https:// timesofindia.indiatimes.com/city/hyderabad/Satellite-TV-racket-busted-inHyderabad/articleshow/37482679.cms.

${ }^{27}$ On digital networks of film piracy, see Virginia Crisp, Film Distribution in the Digital Age: Pirates and Professionals (Basingstoke: Palgrave Macmillan, 2015).

${ }^{28}$ Madeleine Heffernan, "Foul Called on Television's Pirate Broadcasts," The Sydney Morning Herald, June 28, 2014, https://www.smh.com.au/business/foul-calledon-televisions-pirate-broadcasts-20140627-3az1q.html.

${ }^{29}$ Adrian Athique, "The Global Dynamics of Indian Media Piracy: Export Markets, Playback Media and the Informal Economy," Media, Culture E Society 30 (5, 2008): 701.

${ }^{30}$ Ibid., 703-04.

${ }^{31}$ Until the mid-2000s, prior to the larger influx of migrants from the Indian subcontinent, such businesses were concentrated in the Melbourne suburbs of Dandenong and Clayton. See Salim Lakha and Michael Stevenson, "Indian Identity in Multicultural Melbourne: Some Preliminary Observations," Journal of Intercultural Studies 22 (3, 2001): 245-62.

${ }^{32}$ Ibid.; see also Adrian Athique, "Bollywood and 'Grocery Store' Video Piracy in Australia," Media International Australia 121 (2006): 41-51.

${ }^{33}$ Athique, "Bollywood and 'grocery store' Video Piracy in Australia," 46.

${ }^{34}$ Todd Gitlin, "Public Sphere or Public Sphericules?," in Media, Ritual and Identity, ed. Tamar Liebes and James Curran (London: Routledge, 1998), 175-202; Stuart Cunningham, Gay Hawkins, Audrey Yue, Tina Nguyen, and John Sinclair, "Multicultural Broadcasting and Diasporic Video as Public Sphericules," American Behavioral Scientist 43 (9, 2000): 1533-47.

\section{Bibliography}

Aksoy, Asu, and Kevin Robins. "Thinking across Spaces: Transnational Television from Turkey." European Journal of Cultural Studies 3, no. 3 (2000): 343-65. 
Athique, Adrian. 'Bollywood and "Grocery Store'Video Piracy in Australia." Media International Australia 121 (2006): 41-51.

Athique, Adrian. "The Global Dynamics of Indian Media Piracy: Export Markets, Playback Media and the Informal Economy." Media, Culture E Society 30, no. 5 (2008): 699-717.

Bogost, Ian, and Nick Montfort. "New Media as Material Constraint: An Introduction to Platform Studies." Paper presented at the 1st International HASTAC Conference, Duke University, Durham, NC, April 19-21, 2007. http://www.bogost.com/down loads/bogost\%20montfort\%20hastac.pdf.

Bogost, Ian, and Nick Montfort. Racing the Beam: The Atari Video Computer System. Cambridge, MA: The MIT Press, 2009.

Clifford, James. "Diasporas." Cultural Anthropology 9, no. 3 (1994): 302-38.

Crisp, Virginia. Film Distribution in the Digital Age: Pirates and Professionals. Basingstoke: Palgrave Macmillan, 2015.

Cunningham, Stuart, Gay Hawkins, Audrey Yue, Tina Nguyen, and John Sinclair. "Multicultural Broadcasting and Diasporic Video as Public Sphericules." American Behavioral Scientist 43, no. 9 (2000): 1533-47.

Cunningham, Stuart, and John Sinclair, eds. Floating Lives: The Media and Asian Diasporas. Brisbane: University of Queensland Press, 1999.

Curtin, Michael. Playing to the World's Biggest Audience: The Globalization of Chinese Film and TV. Berkeley: University of California Press, 2007.

Curtin, Michael, and Hemant Shah. Reorienting Global Communication: Indian and Chinese Media beyond Borders. Champaign: University of Illinois Press, 2010.

Evans, David S., and Richard Schmalensee. Paying with Plastic: The Digital Revolution in Buying and Borrowing. 2nd ed. Cambridge, MA: The MIT Press, 2015.

Gillespie, Tarleton. "The Politics of 'Platforms'." New Media E Society 12, no. 3 (2010): 1-19.

Gitlin, Todd. "Public Sphere or Public Sphericules?" In Media, Ritual and Identity, edited by Tamar Liebes and James Curran, 175-202. London: Routledge, 1998.

Helmond, Anne. "The Platformization of the Web: Making Web Data Platform Ready." Social Media + Society 1, no. 2 (2015): 1-11.

Keane, Michael. The Chinese Television Industry. London: British Film Institute, 2015.

Lakha, Salim, and Michael Stevenson. "Indian Identity in Multicultural Melbourne: Some Preliminary Observations." Journal of Intercultural Studies 22, no. 3 (2001): 245-62.

Lobato, Ramon. "Evolving Practices of Informal Distribution in Internet Television." In Routledge Companion to Global Television. London: Routledge, in press.

Lotz, Amanda. "Are Facebook, Google, and Amazon the Future of Media?" Council for the Humanities, Arts and Social Sciences Public Lecture, April 4, Queensland University of Technology, Brisbane, Australia. 
Mallapragada, Madhavi. "Mixed Signals: MTV Desi, South Asian American Audiences and the Discourse of Ethnic Television." South Asian History and Culture 3, no. 4 (2012): 549-65.

Mitra, Ananda. "The Trans-Indian: Perspectives on Real vs. Virtual Identity in the Age of the Internet." In Indian Transnationalism Online: New Perspectives on Diaspora, edited by Ajaya Kumar Sahoo and Johannes G. de Kruijf, 47-61. London: Routledge, 2016.

Naficy, Hamid. "Narrowcasting in Diaspora: Middle Eastern Television in Los Angeles." In The Media of Diaspora: Mapping the Globe, edited by Karim H. Karim, 51-62. London: Routledge, 2003.

Plantin, Jean-Christophe, Carl Lagoze, Paul N. Edwards, and Christian Sandvig. "Infrastructure Studies Meet Platform Studies in the Age of Google and Facebook." New Media E Society 20, no. 1 (2016): 293-310.

Punathambekar, Aswin, and Shanti Kumar. Television at Large in South Asia. London: Routledge, 2015.

Sakr, Naomi. "Diversity and Diaspora: Arab Communities and Satellite Communication in Europe." Global Media and Communication 4, no. 3 (2008): 277-300.

Srnicek, Nick. Platform Capitalism. Cambridge: Polity Books, 2016.

Tsagarousianou, Roza, and Jessica Retis. "Diasporas, Media, and Culture: Exploring Dimensions of Human Mobility and Connectivity in the Era of Global Interdependency." In The Handbook of Diasporas, Media, and Culture, edited by Roza Tsagarousianou, 1-20. London: Routledge, 2019.

van Dijck, Jose, Thomas Poell, and Martijn de Waal. The Platform Society: Public Values in a Connective World. Oxford: Oxford University Press, 2018. 